\title{
Evaluation of gingival conditions and saliva TNF- $\alpha$ concentration in children with acute lymphoblastic leukemia
}

\begin{abstract}
Introduction. Patients with the history of neoplastic disease in childhood and adolescence, successfully treated, are at higher risk in terms of their susceptibility to develop other diseases later in their lives.

Aim. The purpose of study was to evaluate saliva TNF- $\alpha$ concentration in the children with acute lymphoblastic leukemia with reference to gingival inflammations.

Material and methods. The investigation was carried out in the group of 78 children with ALL aged 2-18yrs and analogical in terms of age and gender group of healthy controls. Results. Gingival conditions were expressed as gingival index (GI). In the group of children with ALL mean GI determined in examination 1 was $0.084 \pm 0.34$, in examination $2 \mathrm{GI}=0.007 \pm 0.04$ and in examination 3 mean $\mathrm{GI}=0.017 \pm 0.13$. In the group of healthy controls $\mathrm{GI}=0.003 \pm 0.03$. Saliva concentration of TNF- $\alpha$ determined in the group of children with ALL in examination 1 ranged $4.16-135.01 \mathrm{pg} / \mathrm{ml}$. In that group in examination 1 , mean saliva TNF- $\alpha$ concentration was $36.9 \pm 32.6 \mathrm{pg} / \mathrm{ml}$. In the group of healthy children mean saliva TNF- $\alpha$ concentration was $52.1 \pm 107.64 \mathrm{pg} / \mathrm{ml}$.

Conclusions. The authors, who observed various increases in the concentrations of TNF- $\alpha$, IL-1 $\alpha$, IL- 6 , and IL-8 in the saliva and oral tissues in the patients consider that the proinflammatory cytokines in the saliva present in significantly higher concentrations in the future may have diagnostic and predicative value as replace indices of neoplastic transformations.

Monitoring of prognostic factors affecting inflammations of the oral mucosa in children with ALL is likely to prevent complications to standard treatment and prolonged time of anticancer therapy. Early evaluation of those parameters can quicken recovery and strengthen patient's health. Close cooperation between dentists and pediatricians-hematologists is important in maintaining oral health and improve the quality of life of children suffering from neoplastic diseases.
\end{abstract}

Keywords: children, ALL, saliva TNF- $\alpha$ concentration, gingival conditions.

DOI: $10.2478 /$ pjph-2014-0018

\section{INTRODUCTION}

Patients with the history of neoplastic disease in childhood and adolescence, successfully treated, are at higher risk in terms of their susceptibility to develop other diseases later in their lives. Their growth and development of tissues is affected by earlier therapy for juvenile neoplasms they received. The evaluation studies into various stress situations and lowered psychic immunity in the group of children with the past history of neoplasms proved that fully active lifestyle and good socio-economic status allow for the reduction of pathologies and improve their quality of life [1].

Children with acute lymphoblastic leukemia (ALL) are a group that requires special care and health promotion, prophylactic pro-healthy behaviors and therapeutic activities which should be undertaken during diagnostic process, early treatment as well as directed towards those who were cured. The individuals who received chemotherapy, radiotherapy or surgery are likely to develop late chronic complications or health problems many years, even decades following the completion of their treatment, e.g. subclinical symptoms of cardiomyopathy. Although such complications can easily be predicted on the basis of treatment applied, there are numerous other factors that account for the failure of treatment. The degree of risk varies. Complications may be genetically conditioned, affected by lifestyle or other concomitant health problems [2-5].

Anticancer pharmacological treatment can result in lesions affecting the oral mucosa, including altered concentration of salivary cytokines. Complications affecting the alimentary tract including the oral cavity can require modified treatment protocol which adversely affects final therapeutic outcome [6-8].

\footnotetext{
AIM

The purpose of study was to evaluate saliva TNF- $\alpha$ concentration in the children with acute lymphoblastic leukemia with reference to gingival inflammations which are likely to cause treatment difficulties and prolong anticancer treatment time.
} 


\section{MATERIAL AND METHODS}

The investigation was carried out in the group of 78 children with ALL aged 2-18yrs and analogical in terms of age and gender group of healthy controls. In the group of examined children 5 had recurrent neoplasms located in the brain and spinal cord, 2 children had recurrent bone marrow cancer, 7 children had their CNS affected and 3 children had Down's syndrome. The examination of children with ALL followed three stages: examination 1 performed prior to chemotherapy, examination 2 - a few days to five months following the onset of chemotherapy, examination 3 carried out after 0.5 to $1.5 \mathrm{yr}$ of anticancer therapy. The treatment followed the protocol of ALLIC BFM 2002 Program. Dental examinations were preformed with basic diagnostic kits in artificial light.

Clinical dental examination of the children with ALL and the control group included the evaluation of gingival condition by Gingival Index (GI) (Löe and Silness). Two hours after morning meal unstimulated saliva samples were taken and TNF- $\alpha$ was determined by TNF- $\alpha$ human EIA. The saliva samples were centrifuged for $15 \mathrm{~min}$ at $5,000 \mathrm{rpm}$. Centrifuged saliva was frozen at $-80^{\circ} \mathrm{C}$ and stored until laboratory tests.

The results were analyzed statistically. Measurable parameters were presented as means, medians, minimum, maximum and SD. U-Man-Whitney test was used to compare two independent groups, the Spearman R correlation coefficient significance test was used and Wilcoxon's test to compare dependent groups. Statistical analysis was done by STATISTICA 10.0, $\mathrm{p}<0.05$ was assumed statistically significant.

\section{RESULTS}

The results of examinations in both groups and statistical analysis were listed in tables 1 and 2 and graphically presented on Figures 1-4.

Gingival conditions were expressed as gingival index (GI). In the group of children with ALL mean GI determined in examination 1 was $0.084 \pm 0.34$, in examination 2 $\mathrm{GI}=0.007 \pm 0.04$ and in examination 3 mean $\mathrm{GI}=0.017 \pm 0.13$. In the group of healthy controls $\mathrm{GI}=0.003 \pm 0.03$. GI values were statistically significantly higher in the group with ALL prior to treatment in comparison to the control group (Table 1). In the group with ALL GI determined in examination 1 ranged $0-1$ in $6.45 \%$ children while GI $>1$ was noted in $4.84 \%$ children. In this group mean GI determined over 1 to 5-month period of treatment was higher compared to the control group, however the differences between those groups were not statistically significant. Mean GI $>1$ was observed in $3.17 \%$ children with ALL in examination 2 . It can be explained by the fact that gingival inflammations occurred in that period with lesser frequency compared to examination 1. In examination 3 the children with ALL had higher GI in comparison to the control group; the differences were statistically insignificant though. Similarly to examination 2, GI $>1$ was noted in $3.17 \%$ children with ALL. The results found higher frequency of gingival inflammations in children with ALL on chemotherapy compared to the healthy controls.
TABLE 1. Gingival conditions expressed as GI in children with ALL and healthy controls.

\begin{tabular}{|c|c|c|c|c|c|c|c|c|}
\hline \multicolumn{2}{|c|}{$\begin{array}{l}\text { Studied group } \\
\text { of children }\end{array}$} & $\bar{X}$ & $\mathrm{Me}$ & $\min$. & $\max$ & SD & $\mathrm{Chi}^{2}$ & $\begin{array}{c}\text { Significance } \\
\text { level }\end{array}$ \\
\hline \multirow{3}{*}{ ALL } & $\begin{array}{l}\text { examina- } \\
\text { tion } 1\end{array}$ & 36.9 & 35.5 & 4.16 & 135.01 & 32.6 & 0.462 & 0.5188 \\
\hline & $\begin{array}{l}\text { examina- } \\
\text { tion } 2\end{array}$ & 28.2 & 22.4 & 2.43 & 92.36 & 20.4 & 0.6363 & 0.4250 \\
\hline & $\begin{array}{l}\text { examina- } \\
\text { tion } 3\end{array}$ & 28.9 & 18.9 & 2.95 & 171.8 & 28.8 & 2.8949 & 0.0890 \\
\hline \multicolumn{2}{|c|}{ Healthy } & 52.1 & 26.6 & 3.77 & 602.49 & 107.6 & \multicolumn{2}{|c|}{$\begin{array}{c}\text { The above } \\
\text { values refer } \\
\text { to healthy children }\end{array}$} \\
\hline
\end{tabular}

Saliva concentration of tumor necrotic factor- $\alpha$ (TNF- $\alpha)$ determined in the group of children with ALL in examination 1 ranged $4.16-135.01 \mathrm{pg} / \mathrm{ml}$. In that group in examination 1 , mean saliva TNF- $\alpha$ concentration was $36.9 \pm 32.6 \mathrm{pg} /$ $\mathrm{ml}$. In the group of healthy children mean saliva TNF- $\alpha$ concentration was $52.1 \pm 107.64 \mathrm{pg} / \mathrm{ml}$. Mean saliva TNF- $\alpha$ concentrations (examination 1) were lower in the group of children with ALL in comparison to the healthy controls, however the differences were not statistically significant ( $p>0.05$; Table 2). In examination 2 , saliva TNF- $\alpha$ concentrations ranged $2.43-92.36 \mathrm{pg} / \mathrm{ml}$, mean saliva TNF- $\alpha$ concentration was $28.2 \pm 20.4 \mathrm{pg} / \mathrm{ml}$. In the group of children with ALL mean saliva TNF- $\alpha$ values were lower compared to the control group; however the differences were statistically insignificant ( $>0.05$; Table 2 ). In examination 3 , saliva TNF- $\alpha$ concentrations ranged $2.95-171.8 \mathrm{pg} / \mathrm{ml}$, mean saliva TNF- $\alpha$ concentration was $28.9 \pm 28.8 \mathrm{pg} / \mathrm{ml}$. In the group of children with ALL mean saliva TNF- $\alpha$ values were lower compared to the control group; however the differences were close to statistically significant $\left(\mathrm{Chi}^{2}=2.8949, \mathrm{p}=0.089\right.$; Table 2).

TABLE 2. Saliva TNF-a concentration in children with ALL and healthy controls $(\mathrm{pg} / \mathrm{ml})$.

\begin{tabular}{ccccccccc}
\hline \hline $\begin{array}{c}\text { Studied group } \\
\text { of children }\end{array}$ & $\bar{X}$ & Me & min. & max & SD & Chi $^{2}$ & $\begin{array}{c}\text { Significance } \\
\text { level }\end{array}$ \\
\hline $\begin{array}{c}\text { examina- } \\
\text { tion 1 }\end{array}$ & 36.9 & 35.5 & 4.16 & 135.01 & 32.6 & 0.4162 & 0.5188 \\
\cline { 2 - 2 } $\begin{array}{c}\text { examina- } \\
\text { tion 2 }\end{array}$ & 28.2 & 22.4 & 2.43 & 92.36 & 20.4 & 0.6363 & 0.4250 \\
\hline $\begin{array}{c}\text { examina- } \\
\text { tion 3 }\end{array}$ & 28.9 & 18.9 & 2.95 & 171.8 & 28.8 & 2.8949 & 0.0890 \\
\hline Healthy & 52.1 & 26.6 & 3.77 & 602.49 & 107.6 & $\begin{array}{c}\text { The above } \\
\text { values refer } \\
\text { to healthy children }\end{array}$ \\
\hline
\end{tabular}

Wilcoxon's test revealed no significant differences in patient's saliva TNF- $\alpha$ concentrations between subsequent examinations 1 and $2(Z=0.470317 ; p=0.638129)$ and examination $3(Z=1.626513$; $p=0.103841)$ over the period of anticancer therapy (Figure 1).

The results obtained in the group of children with ALL found no statistically significant correlations between GI and saliva TNF- $\alpha$ concentration determined in examination 1,2 and 3. However, TNF- $\alpha$ concentrations determined in examination 1 and 3 tended to be higher which is likely due to increased TNF- $\alpha$ concentrations in case of gingival inflammations (Figure 2 and 4). Examination 2 found that saliva TNF- $\alpha$ concentration tended to decrease at lowered GI (Figure 3). 


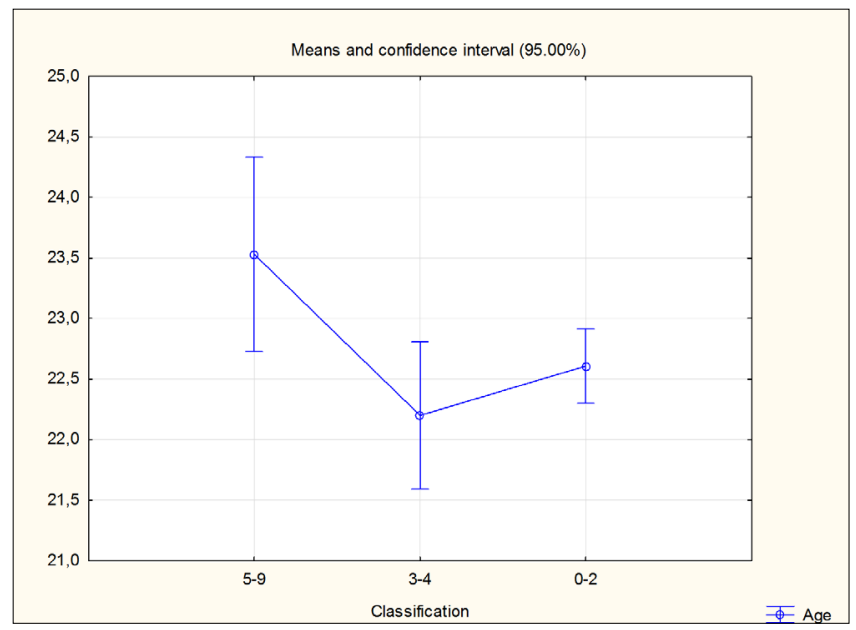

FIGURE 1. Saliva TNF- $\alpha$ concentration in children with ALL in subsequent examinations.

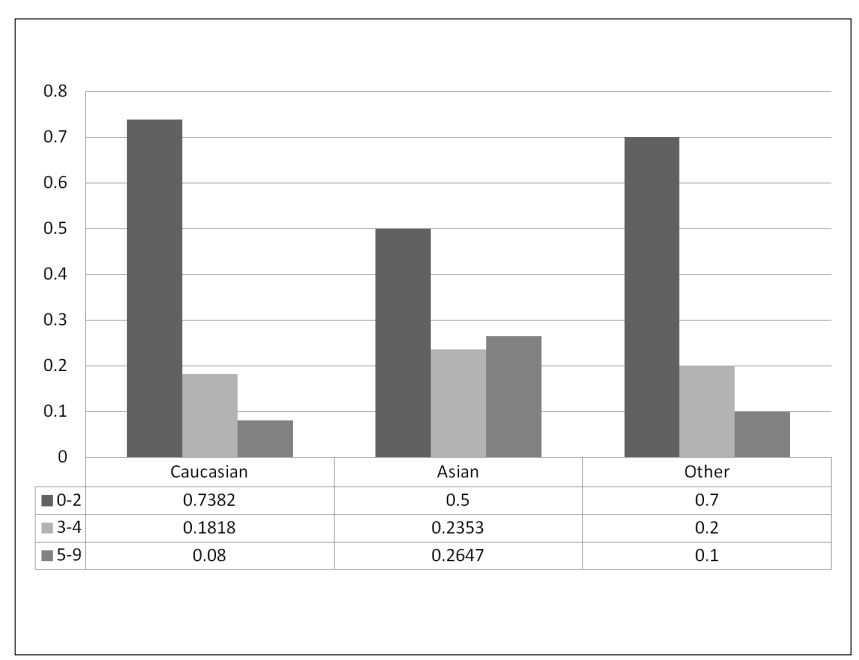

FIGURE 3. GI and saliva TNF- $\alpha$ concentration in children with ALL (examination 2).

\section{DISCUSSION}

The saliva is one of biological materials that has been most frequently used recently to determine biomarkers in various, often serious diseases. As the saliva is collected in a non-invasive way, its samples provide good parameters to diagnose, evaluate effects of treatment and monitor patients' recovery at minimum discomfort for patient and doctor $[9,10]$.

Studies confirmed that some saliva biomarkers such as IFN- $\gamma$, IL-1- $\beta 1$, TNF- $\alpha$, IL-6, IL-4, IL-8 might be useful to predict future course of oral diseases [11]. Cytokine immunoregulatory mechanisms involved in inflammatory processes, infectious and immune diseases affecting the oral cavity play a specific role in host defense and maintaining oral homeostasis. The saliva can provide a good biomaterial to detect proinflammatory markers of oral pathologies [12]. Concentrations of saliva cytokines are likely to replace other biomarkers in the evaluation of chemotherapy effectiveness [13].

Our investigation found that TNF- $\alpha$ concentration tended to increase at increasing GI values in the group of children with ALL in examination 1 and 3. Laskus-Perendyk et al.

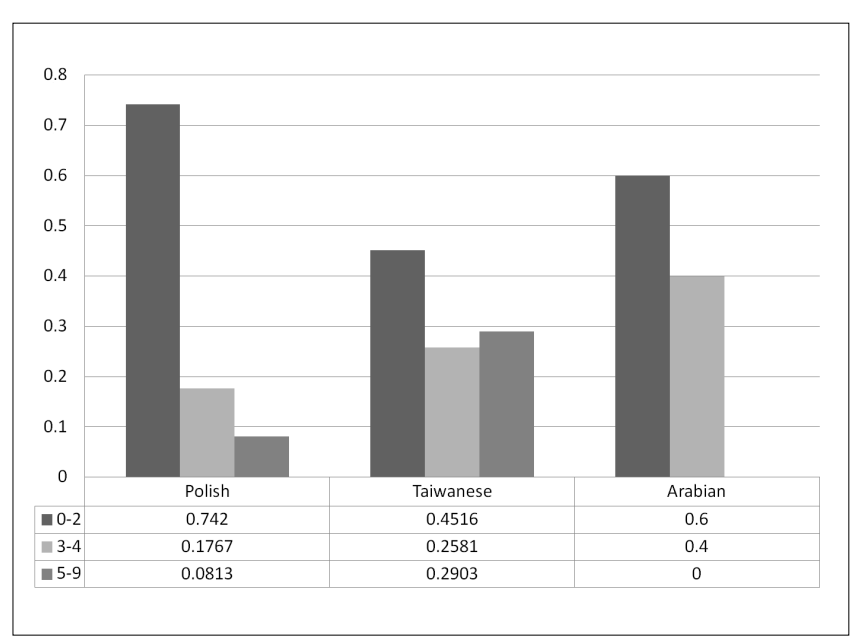

FIGURE 2. GI and saliva TNF- $\alpha$ concentration in children with ALL (examination 1).

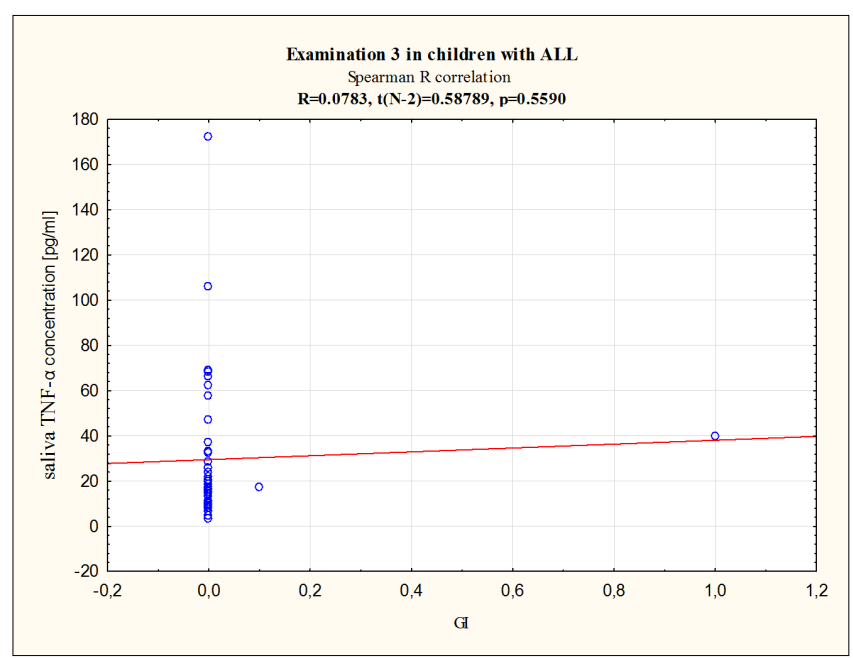

FIGURE 4. GI and saliva TNF- $\alpha$ concentration in children with ALL (examination 3).

examined a group of adults hospitalized for hematological diseases and diseases of the hemopoetic system. They found highest plaque index (PI) in 85\% patients and gingival inflammations in $73 \%$ subjects [14].

Dens et al. observed negative correlation between age and GI $(r=-0.35 ; p<0.05)$ between the group of children on chemotherapy for neoplastic disease (half of them had ALL) and healthy children. In the group of 14-17-year olds $\mathrm{GI}=1.1 \pm 0.1$; in the group of $6-9$-year olds $\mathrm{GI}=1.7 \pm 0.3$ [15]. The study by Fleming and Kinirons did not find any differences in PI and gingival inflammations in children with ALL remission and healthy controls $[16,17]$. Sonis et al. reported on high indices of oral hygiene and gingival condition; they observed significant differences only in the group of patients with ALL on radiotherapy. In the group of children on chemotherapy alone mean GI $=4.7 \pm 3.2$. High index values were due to bigger number of teeth affected by abnormalities and irregular enamel surface [18]. Avsar et al. found significantly higher P1.I and GI in the group of children in complete remission stage in comparison to the healthy children [19]. Uderzo et al. were examining oral conditions in the children (majority of them with ALL) after allo- or autogenic grafts. They found soft deposits in $77.7 \%$ children, gingival 
inflammations in $59.2 \%$ and periodontal pathologies in $3.7 \%$ examined [20]. Lesions of the oral mucosa, i.e. oral ulcerations and reddened areas, however without signs of acute viral inflammations or abscesses were reported by Meyer et al. in $60 \%$ adults with ALL.

TNF- $\alpha$ activates the transcription of NFKB which stimulates cell proliferation, inhibits apoptosis and additionally enhances the secretion of proinflammatory cytokines. The correlation between chronic inflammation and carcinogenesis is well known. Therefore cytokines and other inflammatory mediators are thought to play an essential role in carcinogenesis $[21,22]$. Sonis et al. reported increased blood IL- 1 and IL- 6 correlated with TNF- $\alpha$ concentrations in the patients on chemotherapy [23]. Webb et al. analyzed blood serum cytokines IL-2, IL-3, IL-4, IL-6, IL-10, IL-12, TNF- $\alpha$, and IFN- $\gamma$ in the group of patients with AML, ALL and the control group. They found significant differences in the levels of cytokines between the groups, except IL-2 in the patients with ALL, referred to the healthy controls. The results confirmed the hypothesis on deregulated immune system due to hematologic neoplasms, which can be considered to characterize the disease as well as in treatment [24]. Rhodus et al. observed various increases in the concentrations of TNF- $\alpha$, IL- $1 \alpha$, IL- 6 , and IL- 8 in the saliva and oral tissues in the patients with oral lichen planus. According to the authors, significantly increased salivary proinflammatory cytokines may have diagnostic and predicative value as replace indices of neoplastic transformations [25].

Considering the results of our study and obtained by others, it is impossible to unambiguously claim straightforward and direct correlation between two parameters as various dependences between immune and biochemical salivary characteristics can affect the complexity of oral pathologies. Thus further studies should be postulated to determine biological importance of correlations between saliva cytokines and primary disease, medication and patient's age.

\section{CONCLUSIONS}

1. In the group of children with ALL, GI was statistically significantly increased in comparison to the control group.

2. In the group of children with ALL, mean saliva TNF- $\alpha$ concentration was lower and decreased over the period of chemotherapy; in comparison to the control group the difference was close to statistically significant.

3. Monitoring of prognostic factors affecting inflammations of the oral mucosa in children with ALL is likely to prevent complications to standard treatment and prolonged time of anticancer therapy. Early evaluation of those parameters can quicken recovery and strengthen patient's health.

4. Both parents and children need to be educated on the disease itself, possible complications and threats developing within the oral cavity over the period of chemotherapy. Close cooperation between dentists and pediatricianshematologists seems to be crucial to maintain oral health and improve the quality of life of children suffering from neoplastic diseases.

\section{REFERENCES}

1. Zebrack BJ, Zevon MA, Turk N, et al. Psychological distress in longterm survivors of solid tumors diagnosed in childhood: a report from the childhood cancer survivor study. Pediatr Blood Cancer. 2007;49(1):4751.

2. Bär G, Black PC, Gutjahr P, Stopfkuchenm H. Recovery kinetics of heart rate and oxygen uptake in long-term survivors of acute leukemia in childhood. Eur J Pediatr. 2007;166:1135-42.

3. Małecka-Massalska T, Chara K, Gołębiowski P, et al. Methods of nutrition assessment in patients with head and neck cancer. Zdr Publ. 2013;123(3):253-4.

4. Kamińska M, Ciszewski T, Bronikowska A, et al. The nurse's role in preventing and diminishing side effects after chemotherapy. Zdr Publ. 2013;123(4):325-9.

5. Oeffinger $\mathrm{KC}$, Hudson MM. Long-term Complications Following Childhood and Adolescent Cancer: Foundations for Providing Riskbased Health Care for Survivors. CA Cancer J Clin. 2004;54(4):208-36.

6. Brailo V, Vučićević-Boras V, Cekić-Arambašin A, et al. The significance of salivary interleukin 6 and tumor necrosis factor alpha in patients with oral leukoplakia. Oral Oncol. 2006;42(4):370-3.

7. Bültzingslöwen I, Sollecito TP, Fox PC, et al. Salivary dysfunction associated with systemic diseases: systematic review and clinical management recommendations. Oral Surg Oral Med Oral Pathol Oral Radiol Endod. 2007;103,3(suppl.1):S57.e1-S57.e15.

8. Vučićević Boras V, Brailo V, Lukač J, et al. Salivary interleukin-6 and tumor necrosis factor alpha in patients with drug-induced xerostomia. Oral Dis. 2006;2(5):509-11.

9. Shankar AA, Routray S. Trends in salivary diagnostics - a 5-year review of oral oncology (2007-2011). Oral Oncol. 2012;48(6):e22-3.

10. Wu JY, Yi C, Chung HR, et al. Potential biomarkers in saliva for oral squamous cell carcinoma. Oral Oncol. 2010;46(4):226-31.

11. Scannapieco FA, Ng PBY, Hovey K, et al. Salivary Biomarkers Associated with Alveolar Bone Loss. Ann NY Acad Sci. 2007;1098:496-7.

12. Winkler O, Hadnagy W, Idel H. Cytokines detectable in saliva of children as appropriate markers of local immunity of the oral cavity an approach for the use in air pollution studies. Int $\mathrm{J}$ Hyg Environ Health, 2001;204(2-3):181-4.

13. Rhodus NL, Ho V, Miller CS, et al. NF- $\kappa$ B dependent cytokine levels in saliva of patients with oral preneoplastic lesions and oral squamous cell carcinoma. Cancer Detect Prev. 2005;29(1):42-5.

14. Laskus-Perendyk A, Grzegorczyk-Jaźwińska A, Borakowska M. Zmiany w jamie ustnej pacjentów hospitalizowanych z powodu chorób krwi i układu krwiotwórczego. Nowa Stomatol. 2000;5(1/2):39-42.

15. Dens F, Boute P, Otten J, et al. Dental caries, gingival health, and oral hygiene of long term survivors of paediatric malignant diseases. Arch Dis Child. 1995;72(2):129-32.

16. Fleming P, Kinirons MJ. Study of the dental health of children in remission from acute lymphoblastic leukemia in Northern Ireland. Community Dent Oral Epidemiol. 1993;21(5):309-12.

17. Kinirons MJ, Fleming P, Boyd D. Dental caries experience of children in remission from acute lymphoblastic leukaemia in relation to the duration of treatment and the period of time in remission. Int J Paediatr Dent. 1995;5(3):169-72.

18. Sonis AL, Waber DP, Sallan S, Tarbell NJ. The oral health of long-term survivors of acute lymphoblastic lekaemia: a comparisonof three treatment modalites. Oral Oncol Eur J Cancer. 1995;31B(4):250-2.

19. Avşar A, Elli M, Darka O, Pinarli G. Long-term effects of chemotherapy on caries formation, dental development, and salivary factors in childhood cancer survivors. Oral Surg Oral Med Oral Pathol Oral Radiol Endod. 2007; 104(6):781-9.

20. Uderzo C, Fraschini D, Balduzzi A, et al. Long-term effects of bone marrow transplantation on dental status in children with leukaemia. Bone Marrow Transplant. 1997;20(10):865-9.

21. Jablonska E, Piotrowski L, Grabowska Z. Serum Levels of IL-1 $\beta$, IL-6, TNF- $\alpha$, sTNF-RI and CRP in Patients with Oral Cavity Cancer. Pathol Oncol Res. 1997;3(2):126-9.

22. Philip M, Rowley DA, Schreiber H: Inflammation as a tumor promoter in cancer induction. Semin Cancer Biol. 2004;14(6):433-9.

23. Sonis ST, Elting LS, Keefe D, et al. Mucositis Study Section of the Multinational Association for Supportive Care in Cancer; International Society for Oral Oncology: Perspectives on cancer therapy-induced mucosal injury: pathogenesis, measurement, epidemiology and consequences for patients. Cancer 2004;100(Suppl. 9):1995-2025. 
24. Webb RN, Cruse JM, Lewis RE. Differential cytokine and Toll-like receptor expression in leukemia. Exp Mol Pathol. 2007;83(3):464-70.

25. Rhodus NL, Cheng B, Myers S, et al. A comparison of the proinflammatory, NF-kappaB-dependent cytokines: TNF-alpha, IL-1-alpha, IL-6, and IL-8 in different oral fluids from oral lichen planus patients. Clin Immunol. 2005;114(3):278-83.

\section{Corresponding author}

Elżbieta Pels

Karmelicka 7 St., 20-828 Lublin, Poland

tel. +48 (81) 53-206-19

E-mail: elzbieta.pels@umlub.pl 